\title{
Study of microbial flora in indwelling catheter, drains, CIVP lines and endotracheal tubes
}

\author{
Pradhan $\mathrm{SB}^{1}$, Dhakhwa $\mathrm{R}^{1}$, Shrestha $\mathrm{CD}^{2}$ \\ ${ }^{l}$ Department of Pathology, Kathmandu Medical College and Teaching Hospital, Sinamangal, Kathmandu, Nepal \\ ${ }^{2}$ Department of Microbiology, Kathmandu Medical College and Teaching Hospital, Sinamangal, Kathmandu, Nepal
}

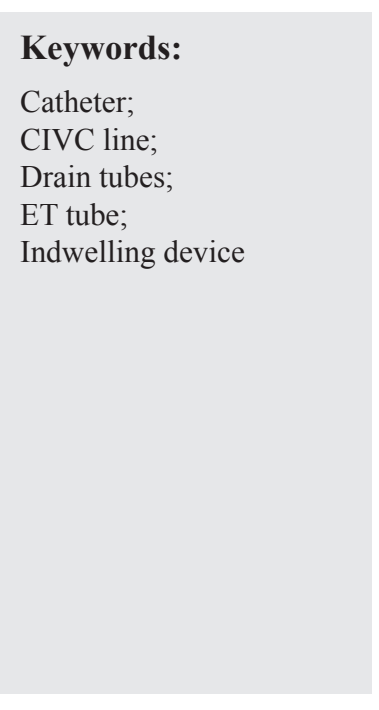

\begin{abstract}
Background: The use of indwelling devices like Urinary catheter, Drain tubes, Central intravascular catheter, endotracheal tubes has become routine practice in the medical field. Localized or systematic infection are frequent complications associated with extensive use of these devices, requiring its removal or may even be associated with life threatening consequences.

Materials and Methods: Microbiological study was carried out among all the indwelling device samples received from 20th April 2011 to 19th April 2012 at Clinical Microbiology Laboratory, Department of Pathology, Kathmandu Medical College Teaching Hospital.

Results: Out of total 205 samples (125 Foley's catheters, 31 drain tubes, 29 central intravascular catheter lines and 20 endotracheal tubes) received during this study period, 38.4\% urinary catheters, $23.33 \%$ drain tubes, $6.9 \%$ central intravascular catheter lines and $40.0 \%$ endotracheal tubes were found to have significant growth. Escherichia coli and Klebsiella were found to be the commonest organisms.

Conclusion: The infection rates of indwelling devices used for various reasons are found to be very high. These infections have increased the morbidity and mortality of the hospitalized patients and also increased the duration of hospital stay. Thus aseptic measurements during insertion of these devices periodic change of these devices may help to overcome these complications.
\end{abstract}

\section{INTRODUCTION}

The use of indwelling devices has become routine practice in the medical field. A significant proportion of hospitalized patients, especially those undergoing major surgery or urinary outflow obstruction like Benign Hyperplasia of Prostate have urethral catheters placed for a short time and patients with bladder dysfunction because of spinal injury, have indwelling catheters permanently. ${ }^{1}$

\section{Correspondence:}

Dr. Sailesh B. Pradhan, MD

Asst. Professor, Dept of Pathology, Kathmandu Medical College Teaching

Hospital, Kathmandu, Nepal

Email:saibinita@gmail.com
Paracentesis is widely employed for palliation of symptomatic malignant ascites, which relieves the pain from abdominal distention and respiratory difficulty from diaphragmatic restricted mobility. Indwelling peritoneal drainage catheter can provide more durable symptom relief, avoiding the hazards and disadvantage of multiple repeat procedures. $^{2}$

Endotracheal tubes (ET) are often used in hospitalized patients usually for brief periods. ${ }^{1}$ Similarly, indwelling central intravascular catheters (CIVC) are used in severely ill patients for therapy and nutrition. ${ }^{3}$ Localized or systematic infections are frequent complaints associated with extensive 
Table 1: Growth patterns in various Indwelling catheter tips

\begin{tabular}{|c|c|c|c|c|}
\hline Sample & Number of samples & Growth pattern & Numbers & Percentage \\
\hline \multirow[t]{9}{*}{ Urethral catheter } & 125 & No growth & 77 & $(61.6 \%)$ \\
\hline & & E. coli & 19 & $(15.2 \%)$ \\
\hline & & Klebsiella & 09 & $(7.2 \%)$ \\
\hline & & Staph. aureus & 06 & $(4.8 \%)$ \\
\hline & & Mixed growth & 06 & $(4.8 \%)$ \\
\hline & & Pseudomonas & 03 & $(2.4 \%)$ \\
\hline & & Strep. fecalis & 03 & $(2.4 \%)$ \\
\hline & & Actinobacter & 01 & $(0.8 \%)$ \\
\hline & & Gram positive cocci & 01 & $(0.8 \%)$ \\
\hline \multirow[t]{5}{*}{ Drain (Chest \& Abdomen) } & 31 & No growth & 27 & $(86.67 \%)$ \\
\hline & & E. coli & 01 & $(3.33 \%)$ \\
\hline & & Klebsiella & 01 & $(3.33 \%)$ \\
\hline & & Proteus & 01 & $(3.33 \%)$ \\
\hline & & Mixed growth & 01 & $(3.33 \%)$ \\
\hline \multirow[t]{3}{*}{ CIVC line } & 29 & No growth & 27 & $(93.1 \%)$ \\
\hline & & Staph. aureus & 01 & $(3.45 \%)$ \\
\hline & & Actinobacter & 01 & $(3.45 \%)$ \\
\hline \multirow[t]{5}{*}{ Endotracheal tube (ET tube) } & 20 & No growth & 12 & $(60.0 \%)$ \\
\hline & & Klebsiella & 04 & $(20.0 \%)$ \\
\hline & & Actinobacter & 02 & $(10.0 \%)$ \\
\hline & & Staph. aureus & 01 & $(05.0 \%)$ \\
\hline & & Pseudomonas & 01 & $(05.0 \%)$ \\
\hline
\end{tabular}

use of these devices, requiring their removal. They may even be associated with life threatening consequences, and lead to increased morbidity and mortality of these hospitalized patients.

\section{MATERIALS AND METHODS}

This study was carried out among the indwelling devices sample received from 20h April, 2011 to 19th April, 2012 at Clinical Microbiology Laboratory, Department of Pathology, Kathmandu Medical College Teaching Hospital. A total of 205 samples (125 Foley's catheters, 31 drain tubes, 29 CIVP lines and 20 ET tubes) were received during this study period.

The tip of indwelling devices were inoculated in Blood agar and Chocolate agar, and incubated overnight at $370 \mathrm{C}$. The plates were read the next day for any growth. Identification of bacteria from culture plates were done with the standard microbiological techniques. ${ }^{4}$

\section{RESULTS}

Out of 205 samples from different tubes (125 Foley's catheters, 31 drain tubes, 29 CIVP line and 20 ET tubes), $38.4 \%$ urinary catheters, $13.33 \%$ drain tubes, $6.9 \%$ CIVP line and $40.0 \%$ ET tubes were found to have significant growth. Escherichia coli and Klebsiella were found to be the commonest organism. Growth patterns in various indwelling catheter tips are shown in table 1.

\section{DISCUSSION}

Much of the success of modern medicine is related to medical devices that support or monitor basic body functions. However, despite technological advances and improvements in the materials and design of devices, infection continues to be a major complication of their use. By their very nature, these devices carry a risk of nosocomial infection, because they bypass normal defense barriers, providing microorganisms' access to normally sterile fluids and tissues. Such infections quite frequently cause serious dysfunction of the prosthesis, requiring its removal, or may even be associated with life-threatening local or systemic consequences.

Urinary tract infection (UTI) accounts for 40 to $50 \%$ of all nosocomial infections, and at least $80 \%$ of these are associated with catheterization. Although Escherichia coli is still a leading cause of nosocomial UTIs, other Enterobacteriaceae and Pseudomonas are more likely than in the community setting. ${ }^{5}$

In this study, 38.4\% Urinary catheters were found to have significant growth and E. coli was found to be the commonest organism whereas in a study done by Taiwo SS et $\mathrm{al}^{6}, 88.5 \%$ 
had significant bacteriuria with E. coli being the commonest organism. Similarly, in a study done by Deep A et al, ${ }^{7} 69.6 \%$ catheters were found to have microbiological growth with Klebsiella being the commonest followed by E. coli.

Out of 31 peritoneal and chest drainage catheters employed for symptomatic relief of the pain from abdominal distention and respiratory difficulty, $13.3 \%$ were found to have significant growth. Likewise, in studies done by Lee A et al and by Belfort MA et al, $16.2 \%$ and $11.8 \%$ of drain tubes were found to have growths respectively., ${ }^{2,8}$ Since ascitic and pleural fluid provide rich culture media and the presence of catheter opens a port for bacteria to enter the cavity, the high rate of infection is not unexpected.

Indwelling central intravascular catheters (CIVC) are used in severely ill patients for therapy and nutrition. Infectious complications associated with the use of these devices have been reported to range from 2.7 to $21 \% .{ }^{9-16}$ In our study, the infection rate was $6.9 \%$. Common skin contaminants, either infecting or colonizing insertion sites, may have been responsible for catheter infections leading to bacteremia. A breakdown in aseptic technique can account for organisms from a distant site seeding the insertion site and then involving the catheter.

Prosthetic airways are used principally in hospitalized patients, usually for brief periods. These artificial airways may interfere with respiratory tract defense mechanisms. The current of inhaled air passing through the smooth lumen of the endotracheal tube bypasses the angulations and mucosa of the upper respiratory tract. The airway also may traumatize the tracheal mucosa and

interrupt normal ciliary cell clearance functions. ${ }^{17,18}$ Machines that assist or control respiration by pumping air directly into the trachea have a great potential for nosocomial pneumonia if the aerosol they deliver becomes contaminated.

In a study done by Deep A et al, 77.8\% endotracheal tubes were found to have microbiological growth while in our study, only $40.0 \%$ endotracheal tubes were found to have significant growth. ${ }^{7}$

It is important to identify the spectrum of microorganisms in order to decide about the routes of infection and to take preventive measures and to decide empirical antibiotic therapy while limiting the emergence of antibiotic resistant organisms.

\section{CONCLUSION}

The infection rates of indwelling devices used for various reasons are found to be very high. These infections have increased the morbidity and mortality of the hospitalized patients. The infections lead to extra hospital stay and expenditure thus over burdening the health economy. Thus aseptic measurements during insertion of these devices periodic change of these devices may help to overcome these complications.

\section{REFERENCES}

1. Dickinson GM, Bisno AL. Infections Associated with Indwelling Devices: Infections Related to Extravascular Devices: Antimicrobial agents and chemotherapy 1989;33:602-7.

2. Lee A, Lau TN, Yeong KY. Indwelling catheters for the management of malignant ascites. Support Care Cancer 2000;8:493-9.

3. Haslett TM, Isenberg HD, Hilton E, Tucci V, Kay BG, Vellozzi EM. Microbiology of indwelling central intravascular catheters. J Clin Microbiol 1988;26:696.

4. Cheesbrough M. Medical Laboratory Manual for Tropical Countries. Ist. ed. (vol. II), The Thehford press Ltd: England; 1984.146pp.

5. Ananathanarayan R, Paniker CKJ. Textbook of Microbiology, 8th Ed.: Universities Press Pvt. Ltd: India; 2009.624pp.

6. Taiwo SS, Aderounmu AOA. Catheter associated urinary tract infection: Aetiologic agents and antimicrobial susceptibility pattern in Ladoke Akintola University teaching hospital, Osogbo, Nigeria. Afr. J. Biomed 2009;9:141-8.

7. Deep A, Ghildiyal R, Kandian S, Shinkre N. Clinical and Microbiological Profile of Nosocomial Infections in the Pediatric Intensive Care Unit (PICU): Indian Pediatrics 2004;41:1238-46.

8. Belfort MA, Stevens PJd'E, DeHaek K, Soeters R, Krige EJ. A new approach to the management of malignant ascites; a permanently implanted abdominal drain. Eur J Surg Oncol 1990;16:47-53.

9. Bentley DW, Lepper MH. Septicemia related to indwelling venous catheters. J. Am. Med. Assoc 1968;206:1749-52.

10. Bernard RW, Stahl WM, Chase RM. Subclavian vein catheterization: a prospective study. Infectious complications. Ann Surg 1971;173:191-200.

11. Brereton RB. Incidence of complications from indwelling venous catheters. Del Med J1969;41:1-8.

12. Collignon, PJ, Munro R, Sorrell TC. Intravenous device related sepsis: a prospective survey. Med J Aust 1984;141:345-8.

13. Collins RN, Braun PA, Zinner SH, Kass EH. Risk of local and systemic infection with polyethylene intravenous catheters: a prospective study of 213 catheterizations. N Engl J Med 1968;279:340-3.

14. Freeman JB, Lemire A, Maclean LD. Intravenous alimentation and septicemia. Surg Gynecol Obstet 1972;135:708-12.

15. Goldmann DA, Maki DG. Infection control in total parenteral nutrition. J Am Med Assoc1973;223;1360-64.

16. Maki DG, Goldmann DA, Rhane SF. Infection control of intravenous therapy. Ann Intern Med1973;79:867-87.

17. Kastanos N, Miro RF, Perez AM, Mix AX, Agusti-Vidal A. Laryngotracheal injury due to Endotracheal intubation: incidence, evolution and pre-disposing factors. Crit Care Med1983;11:362-7.

18. Klainer AS, Turndor H, Wu WH, Maewal H, Allender P. Surface alterations due to endotracheal intubation. Am J Med1975;58:67483. 